\title{
LIMITING COLLUSION IN THE CONSTRUCTION INDUSTRY: A REVIEW OF THE BID-RIGGING SETTLEMENT IN SOUTH AFRICA
}

\author{
Hardin Ratshisusu* \\ Competition Commission, South Africa \\ mratshisusu@yahoo.com
}

Received: June 2014

Accepted: September 2014

\begin{abstract}
This paper undertakes a critical case analysis of the process and outcomes of the Competition Commission (CCSA) Fast Track Construction Settlement Project relative to the mandates of the CCSA and the Construction Industry Development Board (CIDB). The study reviews the information from the CCSA's settlements, analysing the breakdown by private and public projects, type of project and the nature of bid-rigging. It provides an assessment of the practices involved and considers the cooperation that is required for the successful implementation of large infrastructure projects and how these can be organized in a way that ensures rivalry while enabling co-operation. The paper further reviews the barriers to entry, and the complementary measures that can be taken to ensure greater effective rivalry and participation. Interventions that could be necessary at the regulatory, procurement and firm level to ensure that the construction sector charts a new sustainable competitive path are highlighted.
\end{abstract}

Keywords

Regulation, construction industry, entry barriers, corporate leniency, cartel behaviour

Mr H Ratshisusu is a Research Fellow, Centre for Competition, Regulation and Economic Development, University of Johannesburg; Divisional Manager Mergers and Acquisitions, Competition Commission, South Africa. 


\section{INTRODUCTION}

The confirmation of settlements by the Competition Tribunal of South Africa (Competition Tribunal) in July 2013 marked a major milestone in the Competition Commission of South Africa's (CCSA) investigation of bid-rigging and collusion in the construction sector. With 140 projects affected by the collusive practices eligible for settlement, the CCSA reached a settlement with firms on 57 projects for a combined administrative penalty of Rl.46 billion.

Investigations of collusive practices in the construction sector are not unique to South Africa, as other countries such as the United Kingdom (UK), United States of America (USA), South Korea and Netherlands have looked into similar issues before (Haberbush, 2000; Lee \& Hahn, 2002; Sohail \& Cavill, 2008; Gupta, 2001; Dorée, 2004; Porter \& Zona, 1983). This article focuses on the role of the Construction Industry Development Board (CIDB) including the complementary role it can play with the CCSA to ensure firms are discouraged from engaging in collusive practices in the construction industry. There is also a focus on the measures that could be introduced at a regulatory revel to ensure increased rivalry in large infrastructure projects.

In order to assess the construction sector and particularly the role of the CIDB in limiting construction industry cartels, the study sought to unpack the regulatory barriers to entry in the construction industry and how the market could be open for more participation, structural factors that may contribute to bid-rigging, ways in which competition can work as well as interventions that could contribute to a transparent, yet competitive, bidding process.

Primary and secondary data was used to assess the questions of the case study. The primary data was collected through face-to-face unstructured interviews with the key informants identified from the CIDB, the South African National Roads Agency Limited (SANRAL), City of Cape Town, G. Liviero Civils and Fikile Construction. Other identified informants from the City of Johannesburg, Ethekwini Municipality, National Treasury, Giuricich Construction, GD Irons Construction, Group Five, PPC Limited (PPC) and the South African Local Government Association (SALGA) were contacted but did not respond to the request for interview. The views of the contacted informants provide a fair and balanced representation of the construction industry as they cover the regulator, a major metropolitan municipality, firms that were implicated in bidrigging as well as a large infrastructure projects client. The secondary data was obtained from the settlements concluded between the CCSA and construction firms, CIDB regulations and articles in financial and business magazines.

The paper thus presents an overview of the investigations conducted by the CCSA in the construction sector with particular emphasis on the form of collusive practices uncovered. Although the CIDB has legislation and regulations designed to ensure that the construction sector is competitive, develops and supports emerging contractors, and encourages a code of conduct for contractors, this has not stopped the construction firms from engaging in malpractices such as collusion and other forms of procurement irregularities including submitting phony CIDB grading certificates to secure tenders. An assessment of the regulatory framework and practices in the construction sector shows some gaps that may require interventions to enhance the powers of the CIDB, improve coordination in the procurement of large infrastructure projects and incentivise the firms to compete.

The rest of the paper is organised as follows: section 2 provides a theoretical review on bidding markets as well as some examples of bid-rigging in construction elsewhere; section 3 covers the background of the CCSA's construction investigation and the enforcement of the CIDB Act; 
section 4 provides an analysis of factors that may have contributed to bid-rigging and key interventions that may be considered; and section 5 concludes.

\section{THEORETICAL PERSPECTIVES}

\subsection{Bidding markets in brief}

In the basic form, bidding markets, according to Riley and Samuelson (1981:381), posit a scenario of 'thin markets characterised by a fundamental asymmetry of market position', between a single seller (the client) and numerous buyers (the bidding firms). In such a setting the seller looks to sell the goods or services at the price reflective of the rivalry between the buyers, with most bids/actions requiring a reserve price depending on risk profile of the buyer. The common auction rules are English (known as ascending bids), Dutch (known as the high bids), first-price sealed bid auction and second-price sealed bid auction (the last two known as the Vickrey auctions) (Riley \& Samuelson, 1981; see also Goeree \& Offerman, 2004; Klemperer, 2004).

English or ascending bids are those in which an auction runs until there is no other high bid, whereby the winner is the highest bidder. Dutch bids are run such that the auctioneer starts from the highest price and gradually lowers the price, and the first bidder to take the price wins the bid. English bids can be open or closed, whilst the Dutch bids are open.

With the Vickrey auctions, the first-price sealed bid occurs in a manner that the bidders bid independently, and the one who pitches the highest bid wins. On the other hand, with the second-price sealed bids, bidders bid independently, but the winning highest bid pays the second-best price. The award for the bid on the second-best price is done to minimise the socalled winner's curse.

The auction principles, particularly the Vickrey auction methods, equally apply to bidding for infrastructure construction projects, wherein the client (being the single procurer of services) and the bidding firms engage in a bidding process. In this instance, the client determines a budget for the cost of the service upfront and engage in a bidding process to pick the lowest credible bid within its budget. The accuracy of the client's budget would then determine if the project can be completed within the cost estimates of the winning bid.

Klemperer (2004) also notes that bidding markets are susceptible to collusion as firms can attempt to manipulate the outcome of a bid. The concluded construction sector investigations in such countries as South Africa, UK, South Korea, USA and Netherlands point to the pervasive nature of bid rigging.

\subsection{Bid rigging and public procurement}

It is widely accepted the world over that collusion among firms is the most egregious competition law violation. The extent of bid rigging in public procurement, a form of collusion, led the Organisation for Economic Cooperation and Development (OECD) to adopt Guidelines for fighting Bid Rigging in Public Procurement in 2009, which guidelines preceded the key recommendations made in 2012 for eradicating bid rigging (OECD, 2009 \& 2012). It is expressly recognised by the $0 \varepsilon C D$ that an open, transparent and competitive public procurement is vital to ensure that goods and services procured by governments offer 'value for money' (OECD, 2012). 
However, much as public procurement systems could be stymied by instances of bid rigging, certain procurement rules also contribute to bid rigging (0ECD, 2012). It is therefore important to look into the causes of bid rigging from both the firm and regulatory perspectives.

The $0 \varepsilon C D$ recommends the promotion of competition in public procurement through maximising participation of bidders by focusing on the following interventions (OECD, 2012): first, establishing participation requirements that are transparent, non-discriminatory, and that do not unreasonably limit competition; second, designing, to the extent possible, tender specifications and terms of reference focusing on functional performance; third, allowing foreign firms to bid; and fourth, where possible, allowing smaller firms to participate even if they cannot bid for the entire contract.

Sohail and Cavill (2008) note the pervasive nature of corruption (including bribery, embezzlement, kickbacks and fraud) in the construction sector as a major cause of poor or nondelivery of infrastructure projects. Although there have been measures designed at a global level (like UN and OECD conventions on bribery and corruption), Sohail and Cavill (2008:734) argue that 'these top-down approaches are rarely accompanied by effective enforcement and so have proven largely ineffective', as construction sector-specific mechanisms are seen to be the more effective. In the case of South Africa, construction-specific regulations are under the purview of the CIDB, whose existence could not prevent the widespread construction collusion at least up to 2009.

To root out corruption the construction sector, the main areas of focus should include raising awareness on such matters as ethical standards and good business practices, strengthening professional institutions like trade associations, prevention of corruption, and enforcement and monitoring mechanisms (Sohail \& Cavill, 2008).

Sohail and Cavill (2008) also recommend, among other enforcement and monitoring mechanisms that companies caught out bribing should be 'blacklisted'. As regards transparency and rooting out collusion in construction sector procurement, the views of Sohail and Cavill (2008) accord, in the main, with the best practices recommended by the 0ECD. However, instead of advocating the blacklisting of firms, as Sohail and Cavill (2008) argue, authors such as Haberbush (2000) and Gupta (2001) advocate better-designed bid processes to reduce the incentives for firms to collude.

In assessing the cause of bid rigging in the US public sector procurement, Haberbush (2000) noted the facilitating factors to include the practice of limiting competition from the outset of a bid (pre-qualification), sealed bid process, limited deterrents for bid rigging, difficulties in detecting bid rigging schemes and joint ventures. To counteract bid rigging in public procurement, Haberbush (2000) recommends that procurement processes should require firms to disclose compliance programmes when bidding for work. Other measures include redesign of bid documents to move away from the requirements of awarding tenders to the lowest bid, removing restrictions on bidder eligibility to bid, improving bid evaluation processes in order to detect bid rigging patterns as well as introducing stronger punishment for firms involved in bid rigging (Haberbush, 2000).

\subsection{Rivalry in bidding markets and the profit maximisation problem}

In a market with thriving rivalry, "[a] competitive bidder must determine an optimal bid given its likely costs and the probable distribution of the other firms' bids" (Porter \& Zona, 1983:528). 
The profit maximisation problem for each firm is of the following form (Porter \& Zona, 1983; Lee \& Hahn, 2002):

$$
\max _{b} E \Pi(b)=\left(b-c_{i t}\right) \varphi_{i t}(b)
$$

where $b$ is the submitted bid, $c_{i t}$ is the cost for firm ifor job $t$ and $\varphi_{i t}$ is the probability that the bid for firm $b$ is the winning bid.

The higher the probability of firm $i$ winning the bid, the larger the profits it makes, and vice versa. In the event the firm does not win the bid, it makes zero profits (and incurs minimal costs related to the preparation of the bid). Firms tend to be incentivised to collude through such schemes as bid rotation or submitting complementary bids in order to increase their probability of winning a bid, thereby garnering larger profits and at the same time dampening competition.

However, in a sector such as construction where there is repeated interaction between firms, there could be added incentives for firms to collude. As Gupta (2001:454) explains, “... cooperation results from the common wisdom that if one firm bids aggressively against its rivals, the rivals would bid aggressively on the future projects or in other markets". The interaction between bidders, as Gupta (2001) argues, can also be used by regulators to detect collusive behaviour.

Gupta (2001) established that large contracts are prone to bid rigging and that bid prices are higher when there is repeated interaction between firms in other markets than when there is none (also see Haberbush, 2000). In the construction industry, especially for large contracts, there are generally fewer firms capable to undertake the work, as such repeated interaction between firms tends to be inevitable. The nexus of the issue should therefore be to design bids such that firms, even with repeated interactions, are incentivised to compete.

\subsection{Some evidence of bid rigging}

\subsubsection{USA}

According to Porter and Zona (1983), more than half of cases filed with the antitrust division of US Department of Justice between 1982 and 1988 involved bid rigging or price fixing in a number of auction markets, including construction. Porter and Zona (1983) looked into ways to detect bid rigging in highway construction in the US (New York state) in the 1980s. The state was required to award the bid to the lowest 'responsible' bid, provided the price reasonably accorded with the estimates for the work. The auction took a sealed bid form, where the bids were opened in one room with the bidders present and afterwards the winning bid was announced. Porter and Zona (1983) argue that this bidding practice provided a platform for firms to monitor any collusive arrangement that may have been in operation. Similarly, Gupta (2001) looked into the bids for the construction of highways in the US state of Florida between 1981 and 1986, which followed the same bidding patterns as in the state of New York. The bid rigging patterns observed in New York were also evident in Florida.

\subsubsection{South Korea}

Lee and Hahn (2002) looked into bid rigging in the South Korean public works construction projects by assessing contracts awarded between 1995 and 2000. The bid rigging in South Korea, like in Florida and New York, was implemented by the firms through rotational and 
complementary bidding (or cover pricing). In the latter, other bidders in collusive arrangement, except one, submit the bids to lose (Lee \& Hahn, 2002; Porter \& Zona, 1983; Gupta, 2001).

\subsubsection{UK}

The UK's OFT uncovered widespread bid rigging practices in the construction sector for the investigation period between 2000 and 2006. Investigations were concluded in 2009, with 103 firms found to have been involved in bid rigging (mainly cover pricing, with instances of compensation payments) affecting 199 projects (OFT, 2010). The fines levied amounted to f129.2 million (circa R2.3 billion), although 25 of the fined firms appealed the decision (OFT, 2010). Bid rigging affected both public and private sector projects, with $57 \%$ of the projects public and the rest private (OFT, 2010).

\subsubsection{Netherlands}

In the Netherlands, a 2001 television documentary in which whistle-blowers detailed the extent of bid rigging in the construction industry led to a public outcry and subsequent investigations by the Cabinet, the Department of Justice and the Dutch Competition Authority (Dorée, 2004). In the main, three main factors facilitated the bid rigging in Netherlands (Dorée, 2004). First, the bid rigging scheme was such that when a new entrant was identified in an area, the colluding parties ensured that their bids were so low that they effectively excluded such an entrant from the market. Second, colluding firms had to pay each other compensation for submitting phony bids. Third, transparent selection procedures that had to be followed by public sector clients made it easier for the firms to manipulate the procurement process.

\subsection{What of competition in the construction sector?}

Dorée (2004:154) further argues that " $[t]$ o improve the situation of the construction industry requires further non-conventional procurement methods and less selection based on the lowest bid", in line with "... construction reform policies adopted around the world ..." Key drivers of the construction sector, according to Dorée (2004), should be based on value and quality-driven competition, integrated team delivery and long-term commitments. Dorée (2004:154) asserts that a sector like the construction sector is susceptible to "ruinous competition" and as such competition cannot be sustained.

The Netherlands experience, like in all other countries where there has been bid rigging in the construction sector, shows that both the firms' stratagems and procurement processes facilitate bid rigging (Haberbush, 2000; Lee \& Hahn, 2002; Sohail \& Cavill, 2008; Gupta, 2001; Porter \& Zona; 1983). The main challenge is to ensure that such collusive practices are eradicated at all levels of the procurement chain. Therefore, assertions by others like Dorée (2004) that competition in the construction sector is not feasible suggest that without some form of cooperation between firms the benefits of competition cannot be realised. The construction sector, like any other sector with no features of a natural monopoly, can be competitive if there is rivalry between firms. And, by its very nature, competition is robust such that some firms will prosper while others will not; the solution therefore cannot be cooperation but innovation and rivalry. 


\section{CONSTRUCTION SECTOR INVESTIGATIONS IN SOUTH AFRICA}

\subsection{The investigation at a glance}

The first signs of collusion in the construction industry came as a consequence of a corporate leniency application (CLP) by Murray \& Roberts, through its subsidiary, Rocla, in 2007. This case exposed a cartel in the production of pipes, culverts and manholes as well as bid rigging in the supply of precast concrete products (Competition Tribunal, 2013a; Competition Tribunal, 2010). The cartel, as detailed in the case between the Competition Commission $v$ Southern Pipelines Contractors/Conrite Wal/s, operated from 1973 to 2007 in Gauteng, KwaZulu-Natal and the Western Cape. Having endured for such a long period, the cartel was structured such that one member of the cartel was designated a 'banker' to compile a list of all contracts available during a specific period. Cartel members allocated regions and market share. The effects of the cartel were catastrophic. As the Competition Tribunal (2010:4) explained, "[c]artel members enjoyed a quiet and hugely profitable life, as evidenced by the drop in prices by between $25-30 \%$ post the disbandment of the cartel ..." Further in-depth study of the cartel showed overcharges ranging froml6.5 to $28 \%$ in Gauteng and $51-57 \%$ in KwaZulu-Natal (Khumalo, Mashiane \& Roberts, 2014).

In the light of the uncovered collusion in the construction products involving some of the toptier construction firms, CLPs in the sector as well as international trends on bid rigging, the sector came onto the radar of the CCSA. This led the CCSA to prioritise the broader infrastructure and construction sector in 2008, among other sectors. The focus on the sector was also due to the infrastructure programme government was embarking on and therefore it was vital that prices of inputs to the infrastructure programme were not inflated by anti-competitive behaviour and practices. With the sector in the spotlight, the CCSA embarked on an in-depth study of the entire value-chain of the construction sector and at the same time CLPs started flowing in.

Armed with the information on possible anti-competitive conduct in the sector, the CCSA launched investigations of bid rigging and collusion in the construction sector in 2009. During the investigations, the CCSA established that bid rigging and collusive conduct was rife in the sector. In the circumstances, the CCSA decided, in February 2011, to invite firms involved in bid rigging and collusion to settle their contraventions provided they fully disclose the extent of their involvement and, where applicable, pay an administrative penalty.

In 2013, the CCSA concluded settlements with the majority of firms that were involved in the bid rigging and collusion on various projects, for which the contraventions occurred between 2006 and 2009. The total administrative penalties out of the settlement process amounted to R1.46 billion. TABLES 1 and 2 provide the information on the projects that were affected by the scourge of bid rigging and collusion.

In total, 300 projects were affected by bid rigging and collusion for the period of at least between 2000 and 2009. Of these projects, 160 (53\%) fell outside the prescription period, set out in section 67 of the Competition Act, within which a complaint can be brought against parties involved in prohibited anti-competitive practices, hence the distinction between prescribed and non-prescribed projects in TABLE 1 . 
Ratshisusu

TABLE 1: Projects affected by the construction cartel: Prescribed versus Non-prescribed

\begin{tabular}{llll}
\hline & Prescribed & Non-prescribed & Total \\
\hline Number of projects & 160 & 140 & 300 \\
Number of projects $(\%)$ & $53 \%$ & $47 \%$ & $100 \%$ \\
Value of projects & R9.9 billion & R37.1 billion & R47 billion \\
Value of projects (\%) & $21 \%$ & $79 \%$ & $100 \%$ \\
\hline Total project settled: 57 & & & \\
\hline
\end{tabular}

Source: Competition Commission SA

Notes:

(1) Prescribed projects involved acts of collusion that occurred outside the period permissible to investigate.

(2) Non-prescribed projects involved acts of collusion that occurred within the period permissible to investigate.

Therefore, the projects considered for settlement were those deemed non-prescribed, constituting $47 \%$ of the affected projects. At the conclusion of the CCSA's settlement process, there were settlements on 57 projects out of the total non-prescribed projects of 140, with the latter still under investigation by the CCSA.

The value of the non-prescribed projects amounted to R37.1 billion ( $79 \%$ of the total projects), largely accounted for by the FIFA World Cup stadia construction and the Gauteng Freeway Improvement Plan (GFIP). In terms of value, the CCSA's investigation and settlement covered a substantial portion of the projects affected by bid rigging.

TABLE 2: Projects affected by the construction cartel: Private versus Public

\begin{tabular}{llll}
\hline & Private & Public & Total \\
\hline Number of projects & 75 & 225 & 300 \\
\hline Number of projects $(\%)$ & $25 \%$ & $75 \%$ & $100 \%$ \\
Value of projects & R19 billion & R28 billion & R47 billion \\
Value of projects $(\%)$ & $40 \%$ & $60 \%$ & $100 \%$ \\
\hline
\end{tabular}

Source: Competition Commission SA

The bid rigging and collusion uncovered in the construction sector affected both private and public sector projects. However, most of the rigged projects were for the public sector (75\%), while the rest was for private sector projects $(25 \%)$. In terms of value, the rigged projects for the public and private sector accounted for $60 \%$ and $40 \%$ of the infrastructure spend, respectively. In total, projects to the tune of R47 billion were affected by bid rigging and collusion across the private and public sector projects.

\subsection{Key large infrastructure projects affected}

A number of projects in both public and private sector were affected by the bid rigging and collusion in the construction sector, details of which are found in the settlement agreements 
confirmed by the Competition Tribunal. Firms that settled with the CCSA revealed information about projects in which bid rigging occurred.

In public sector projects, bid rigging affected municipalities and public entities such as $\varepsilon$ skom and SANRAL. The major public sector projects affected were the roads (GFIP) and FIFA Soccer World Cup stadia construction.

In the construction of roads, the top construction firms, namely, Grinaker LTA (an Aveng subsidiary), Basil Read, Haw \& Inglis, WBHO, Concor and Raubex, reached an agreement at the Road Contractors meetings in 2006 to allocate tenders for the construction of roads. In addition, the firms agreed that firms not interested in winning the bid or not allocated a project would submit cover bids to ensure that those interested win the bid, a practice commonly referred to as cover pricing.

Another major project was the construction of the new FIFA Soccer World Cup stadia. The bid rigging agreement was concluded in 2006 by Grinaker LTA, WBHO, Murray \& Roberts, Group Five, Concor and Basil Read. These firms met twice to allocate, among each other, the construction of the stadia, namely, Mbombela (Nelspruit), Peter Mokaba (Polokwane), Moses Mabhida (Durban), Soccer City/FNB Stadium (Johannesburg), Nelson Mandela Bay (Port Elizabeth) and Greenpoint (Cape Town). The firms moreover agreed to exchange cover prices in their respective bids to ensure that the agreed allocations were realised and also agreed on a profit margin of $17.5 \%$ to be attained from the construction of the stadia.

The collusive practices on the construction of roads and stadia were instigated by the top tier of South Africa's construction firms graded for large projects in CIDB's general building and civil engineering categories for grade 9 firms. Although just over 50 firms are registered for CDIB 9 in the $\mathrm{GB}$ and $\mathrm{C} \varepsilon$ categories, in reality only the top tier of these firms are capable of handling large infrastructure projects. No construction firms that have been able to challenge the stronghold of the top-tier construction firms have emerged. This made it easier for the top firms to reach an agreement, as there would be no credible threat of rivalry from the other CIDB 9 category firms.

In the private sector, projects affected included industries/sectors such as mining (Anglo Platinum, Xstrata LionOre), paper and pulp (Mondi and Sappi), university residences (Universities of Pretoria and Cape Town) as well as private residences. The bid rigging uncovered also extended to mining infrastructure projects in Burkina Faso, Zimbabwe and Botswana.

\subsection{Forms of collusive tendering}

The construction sector, as revealed in settlements by firms with the CSSA, has been riddled with collusive practices for a number of years. The extent of such conduct has not been fully exposed in the settlements, as more than half $(53 \%)$ of the rigged contracts were not considered for settlement given that the contraventions had prescribed in terms of the Competition Act (See TABLE 1).

What has been revealed is that the collusive practices took at least four forms, namely, (1) agreement on allocating customers and profit margins to be attained from a contract, (2) cover pricing, (3) payment of loser's fee to a bidder who submitted a cover price, and (4) subcontracting as a means of compensation to losing bidders (CCSA, 2013). Each of these formulations of bid rigging and collusion is discussed in detail below, highlighting how the modus operandi of the firms unfolded. 


\title{
3.3.1 Scenario 1: Allocating customers and fixing profit margins
}

This form of bid rigging occurred mainly at a high level, where firms gathered together to allocate customers for anticipated construction work. The instances uncovered in the settlements were the road contractors' meeting (for anticipated GFIP and other road construction works), FIFA World Cup stadium allocation (for construction of world cup stadia), Wade list meeting (for electrical work) and Cape club meeting (for construction works in the Western Cape).

In the meetings, firms would allocate bids and, in some instances, agree on the profit margins to be attained. The firms were found to have been involved in this form of conduct without the knowledge of the clients.

\subsubsection{Scenario 2: Cover pricing}

Cover pricing has been defined in the settlements as an instance of collusive tendering as follows (Competition Tribunal, 2013):

Cover pricing occurs ... when conspiring firms agree that one or more of them will submit a bid that is not intended to win the contract. The agreement is reached in such a way that among the colluding firms, one firm wishes to win the tender and the others agree to submit noncompetitive bids with prices that would be higher than the bid of the designated winner, or the price would be too high to be accepted, or the bid contains special terms that are known to be unacceptable to the client.

The former C\&O of Aveng explains the finer details of the cover pricing scheme as follows (Jardine, 2013):

\begin{abstract}
The main practice appears to have been what is called "cover-pricing". A strong management system was clearly in place, including succession planning because when one person was promoted or left the company he would bring his successor to a meeting (according to evidence submitted, these meetings usually occurred at 5 star hotels), introduce the new person and do a formal hand-over. Some of the younger people knew that if they wanted to get ahead in their companies this was "the way it is done". The tenders were then allocated as follows: the firm not wanting the business gives a "cover price" to a competitor who then wins the award on submitting a lower price than the "cover price". In some cases, the firm submitting the "cover price" will be compensated through a "losers' fee".
\end{abstract}

The settlement by firms as confirmed by the Competition Tribunal revealed that a significant amount of the collusive tendering was in the form of cover pricing, for both public and private sector contracts. Firms, individually or as joint ventures, decided on cover prices based on capacity constraints or as an act to inflate the bid price.

Cover pricing arising from capacity constraints, often rife in private sector projects, occurs when firms are invited to bid for work and have neither available capacity nor appetite for the work. In this instance, an invited firm would then request a cover price from another firm to bid such that the invited firm does not win the tender. Some of the firms argue that this form of cover price takes place as firms are generally reluctant to turn clients away.

In instances of cover pricing as a means to inflate tender costs, firms would agree on projects they should share among themselves, and use cover pricing to ensure that the outcome is achieved. This form of cover pricing is solely designed to ensure that the rivalry in the identified projects is eliminated, thus making it possible for the firms to extract higher-than-normal profit margins. 
Despite the form of the cover pricing or phony bids, it has been established in the countries that have uncovered bid rigging in the construction sector that such conduct is orchestrated to deceive the buyer that there is competition when there is not, with the ultimate goal of achieving higher prices. In essence, construction firms were able to consistently influence the outcome of bids for infrastructure projects through cover pricing. And as shown in the details of the settled projects affected by bid rigging, firms have been particularly successful in ensuring that contracts are allocated to the chosen firm. In only very few instances of cover pricing (on settled projects) did one of the firms engaged in cover pricing not win the tender (see for example the projects to construct the N2 Section 10-Gamtoos to van Staden River, Peter Mokaba Sports Stadium, Millwood Village Residential Project and Kempton Park City Mall).

Cover pricing has been the form of collusive pricing that has allowed firms to continuously rig bids to influence the outcome of a tender process. In this way firms have been able to allocate contracts, eliminate competition and achieve higher prices than would have been achieved had the bid rigging not occurred.

\title{
3.3.3 Scenario 3: Payment of losers' fee
}

In certain instances, cover pricing was combined with payment of losers' fee, which meant that participants to the cover pricing scheme were paid a losers' fee. This was a ploy by the construction firms to ensure that those participating in the cover pricing scheme were compensated, in some instances with payments in excess of Rl million.

According to the former $\mathcal{C}_{0}$ of Aveng, there was even fraudulent accounting to conceal the losers' fee in the companies' books. In essence, the losers' fees were accounted as follows (Jardine, 2013):

\begin{abstract}
These "losers' fees" were apparently disguised through fake accounts in line items called plant and machinery, scaffolding hire or labour. Money came in and out of these accounts, they kept a score sheet to keep track of who owed monies, invoices were raised, and if another project came up offsets were applied.
\end{abstract}

This from of accounting was, obviously, designed to hide these fraudulent payments from the auditors' radar. The practice of recording losers' fees as plant hire was confirmed by a number of representatives of firms before the Competition Tribunal for settlement hearings, including Esorfranki, Murray \& Roberts and WBHO.

\subsubsection{Scenario 4: Subcontracting}

Collusive tendering also occurred whereby participating firms were guaranteed subcontracting work for submitting false bids to clients. When the identified firm won the tender, participating firms were rewarded with subcontracting work.

In sum, the construction firms engaged in collusive tendering/bid rigging in the form described in the scenarios above. For many years, before the investigations by the CCSA, firms were rigging the procurement processes on major infrastructure projects in South Africa with impunity. As the law has caught up with the firms, the challenge for the industry will be to adapt to a competition culture by abandoning collusive tendering practices. 


\subsection{Enforcement of the CIDB Act}

The CIDB Act established the CIDB in order to implement an integrated strategy for the reconstruction, growth and development of the construction industry. The CIDB Regulations, adopted in 2004, provide a framework for grading contractors in terms of their capabilities and the volume/nature of the projects they can undertake. Initially, the grade of a contractor was based on two methods, one based on the track record and the other on the available capital. The latter method meant that a contractor could achieve a high grading provided it had available capital, regardless of its track record. This led to the amendment of the CIDB regulations in 2013 to provide for a ranking framework based on both the track record and available capital.

The CIDB grades, from 1 to 9 , determine the value of tender a firm can bid for based on its annual turnover, value of projects undertaken and available working capital. This system thus regulates the extent to which firms can participate in bids in the public sector. There are, however, provisions in the CIDB regulations to allow firms to enter into joint ventures, such that they could receive a higher grade in order to bid for certain projects, as shown in table 3.

\section{TABLE 3: CIDB grading for Joint ventures}

\begin{tabular}{|c|c|}
\hline Designation & Deemed to satisfy joint venture arrangements \\
\hline 3 & Three contractors registered in contractor grading designation 2 \\
\hline 4 & Three contractors registered in contractor grading designation 3 \\
\hline 5 & $\begin{array}{l}\text { Two contractors registered in contractor grading designation 4; } \\
\text { One contractor registered in contractor grading designation 4; and } \\
\text { Two contractors registered in contractor grading designation } 3 \text {. }\end{array}$ \\
\hline 6 & $\begin{array}{l}\text { Two contractors registered in contractor grading designation 5; } \\
\text { One contractor registered in contractor grading designation 5; and } \\
\text { Two contractors registered in contractor grading designation } 4 \text {. }\end{array}$ \\
\hline 7 & $\begin{array}{l}\text { Two contractors registered in contractor grading designation 6; } \\
\text { One contractor registered in contractor grading designation 6; and } \\
\text { Two contractors registered in contractor grading designation } 5 \text {. }\end{array}$ \\
\hline 8 & Three contractors registered in contractor grading designation 7 \\
\hline 9 & Three contractors registered in contractor grading designation 8 \\
\hline
\end{tabular}

Source: CIDB Regulations, 2013 (as amended)

The joint venture arrangements set out in the CIDB regulations ensure that firms are provided an opportunity to bid for work that they would otherwise not qualify for individually. For instance, in the case of large projects with a value of over R130 million (grade 9), there is provision for a joint venture by three grade 8 firms, which could provide some scope for competition for grade 9 contractors.

Contractors seeking to bid for public sector contracts have to be registered on the national register of contractors. If a contractor is awarded a public sector contract, and is unregistered, it is liable for a fine not exceeding $10 \%$ of the value of the affected contract. For any other 
offences, a person (legal person) who contravenes the CIDB Act and/or any of its regulations is liable for a fine not exceeding R100000.

Since 2007, the CIDB has sanctioned a number of firms for various contraventions of the CIDB Act and regulations. Firms as well as individual directors have mainly been meted with suspensions for a specified period (generally 6 months to 12 months, and in few cases, up to 60 months), required to reapply for registration, pay a fine not exceeding R100 000 and/or downgraded. FIGURE 1 shows the total number of firms sanctioned by the CIDB between 2007 and 2013, including those that were removed from the register of contractors indefinitely or for five-year period or longer.

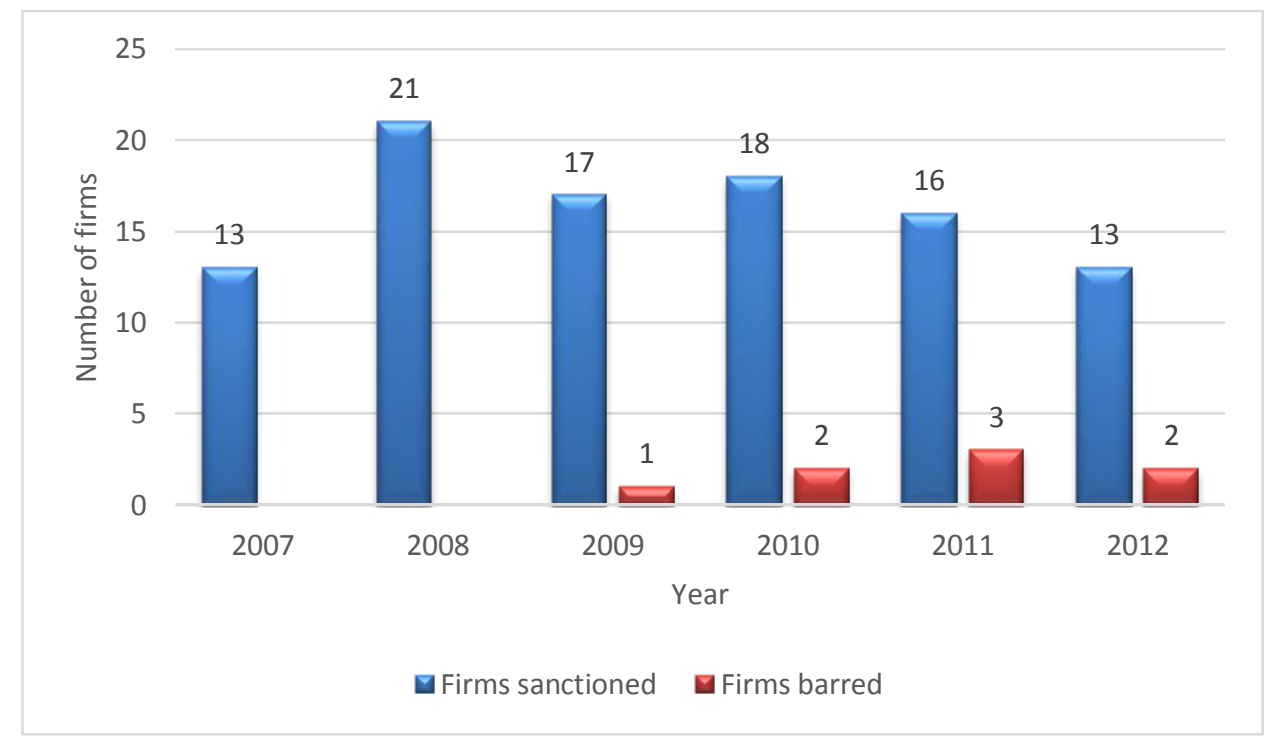

FIGURE 4: Number of firms sanctioned by the CIDB, 2007-2012

Source: CIDB government gazette notices, 2007-2012

Note: Statistics from the CIDB are only available from 2007.

In total, the CIDB has, between 2007 and 2012, sanctioned 98 firms (including their directors) for various forms of irregularities, eight of which were barred from registering indefinitely or for periods of at least five years. The most common contraventions are submitting falsified financial statements, forged tax clearance certificates, inaccurate track records and bogus affiliations of members of staff to various professional associations. In recent times, the CIDB has also sanctioned public sector clients such as government departments for not publishing tenders or for appointing firms that are not on the register of contractors.

\section{ANALYSIS}

There are various measures that could be considered for the South African construction sector to rid it of its collusive tendering practices and move towards realising a competition culture. Due consideration ought to be given to the regulatory environment, procurement management and the behaviour of firms. 
For the construction sector to be competitive, there has to be effective regulatory oversight, transparent procurement practices and competitive rivalry among firms.

\subsection{Regulatory level}

The CIDB is empowered to regulate the construction sector to promote the growth and development of the sector. There are regulatory requirements that firms have to adhere to, particularly with respect to the register of contractors, which the CIDB keeps and uses to grade firms according to their capacity to carry out construction work. The stakeholders engaged cite the CIDB grading of contractors as a necessary tool to ensure that firms in the sector meet certain minimum requirements to undertake projects (Marsden, 2013; Mofokeng, 2013; Ntiisa \& George, 2013; Cloete, 2013; Smit \& Van der Walt, 2013).

There are, however, two main deficiencies in the CIDB grading system.

First, the grading does not provide sufficient information to clients on the capacity and ability of firms to undertake construction works (Smit \& Van der Walt, 2013). It could assist clients if the grade of the contractors matched the capacity and ability of the contractor concerned to undertake a construction project at a given point in time, which information can be made available by the CIDB. For instance, the CIDB grade 9 , which is the highest grading a contractor can attain, has more than 50 firms than can potentially qualify to undertake the large infrastructure projects, but in reality only the top firms like Group Five, Aveng, Murray \& Roberts, Basil Read, Raubex, Stefannuti and WBHO can deliver such projects. The number of firms in the CIDB grade 9 category gives a false impression that there is a high number of large construction firms, whereas competition for large infrastructure firms occurs only between the top firms.

Second, the provisions in the CIDB regulations for joint venture arrangements to allow firms to compete for CIDB grade 9 projects limit that possibility to only a consortium of three grade 8 firms at a time. There is thus no flexibility to allow a group of emerging contractors, at different stages of development, to form consortia to compete for large infrastructure projects. For this reason most of the emerging contactors rely on subcontracting work, thus limiting their potential to grow.

There is also a concern, as indicated by Ntiisa and George (2013), on the penalties provided for in the CIDB Act, in the event of contraventions by firms. At best, the CIDB can deregister a firm from the register of contractors or levy a fine not exceeding R100 000.

Therefore, to ensure that there are fewer incentives for firms to engage in collusive tendering, the following regulatory interventions can be considered:

- Enhancing the powers of the CIDB to deal with procurement irregularities by contractors. This will require that there are appropriate and tougher sanctions such as increasing the quantum of possible fines, to meet the gravity of the procurement irregularities.

- Review of the CIDB grading system to take into consideration the ability of a contractor to execute the work as well as past performance. The thresholds have to be revised to be based on the allowable annual turnover thresholds to ensure that contractors do not take work beyond their capacity to perform. As per the current formulation, the thresholds do not provide a limit on the number of projects a firm can take within a grade, that is, a firm may simultaneously take multiple projects of equal value but lack the capacity to deliver on all. 
- Introducing support measures (e.g. deepening contractor development) and a regulatory framework to enable emerging firms to participate and bid for large infrastructure projects, instead of this being the province of only the top firms.

- Cooperation between the CCSA and CIDB on investigations, particularly on cases involving bid rigging in the construction sector.

The CIDB, with enhanced powers, can contribute to a competitive and efficient construction sector, thus contributing to the attainment of the objectives of both the CIDB Act and Competition Act.

\subsection{Procurement level}

On the procurement level, much of the bid rigging in the large infrastructure projects that were undertaken in South Africa, according to the City of Cape Town and SANRAL, is a result of the way government planned the projects. During the CCSA's investigation period for bid rigging, 2006 to 2009, government launched construction projects for roads (GFIP), FIFA World Cup stadia and Eskom power stations. At the time, there was only a handful of firms that had the proven track record to embark on such large-scale projects. For instance, in roads construction, SANRAL divided the work into packages and invited specific firms to bid for each individual package. As revealed in the Competition Tribunal settlements, the firms (Grinaker/Aveng, Basil Read, Concor/Murray \& Roberts, WBHO, Raubex and Haw \& Inglis) met to discuss the cover pricing scheme such that those firms not interested in the bids submit phony bids. It can be inferred that the availability of other lucrative construction opportunities such as the FIFA World Cup and Eskom power stations provided room for the firms to sacrifice other work. In this regard, most of the stakeholders noted this infrastructure projects glut as the main reason firms sought to collude in order to extract the greatest profit.

In addition, there are noted concerns about the capacity of the government institutions to manage the procurement of large infrastructure projects (Mofokeng, 2013). There is said to be a lack of requisite skills to procure services for large infrastructure projects, such that engineering consulting companies are retained to manage the process on behalf of a government institution. This, in the view of some of the stakeholders is another main contributing factor to bid rigging, as the management of the procurement process is often outsourced to third parties (Marsden, 2013; Mofokeng, 2013).

As indicated by Smit and Van der Walt (2013), the nature of the procurement process for public sector projects, particularly the requirement that projects must be awarded to the lowest qualifying bid, also contributes to bid rigging, since firms can easily pick whose bid should be the lowest. In most instances where cover pricing was found, the tender was awarded in line with the cover pricing scheme devised by the firms. This may call for a consideration of other criteria to evaluate prices. It has also been found that the lowest qualifying bid principle invariably leads to the winner's curse, as some firms would price too low to secure a project but with no available capacity to undertake such work.

There are also concerns noted in private sector infrastructure projects, particularly as regards the role of consulting engineering firms tasked to manage procurement (Mofokeng, 2013; Cloete, 2013). As there is no express requirement for a public procurement process in private sector projects, the consulting firms are often provided the latitude to identify and recommend suitable contractors for a project. When firms are contacted by the consulting engineers for such projects, they tend to agree to participate in the tender process even in instances where they do 
not have the available capacity to undertake the work. The lack of capacity in some of the firms identified to participate in a tender process results in them requesting their competitors to provide a cover bid such that the outcome of the bidding process is manipulated.

To counteract future acts of bid rigging in large infrastructure projects at the procurement level, the following potential key interventions are necessary (see also 0ECD, 2012):

- Government should consider spreading out the expenditure on large infrastructure projects over a longer time horizon. The local construction industry did not have the capacity to undertake the number of large projects such as GFIP and Eskom power stations and FIFA World Cup stadia that were initiated in the same period. In essence, the expenditure should be aligned with the capacity of local construction industry to absorb the work.

- There has to be consideration on the options to split large construction projects into packages to allow for broader participation by construction firms. This would ensure that contractors that would otherwise not qualify for one large project could successfully bid for individual packages. However, such packaging of projects should be designed in a manner that does not compromise the quality of a given project.

- Instead of rules that require projects to be awarded to the lowest qualifying bid, a consideration should be given to the benchmarking model (or other alternative models) whereby the winning bid is based on a range of the prices of the bids at some percentile (see also Haberbush, 2000). The benchmarking model is similar to second-price sealed bids (one type of Vickery auctions) in which bidders bid independently, but the winning highest bid pays the second-best price. In the case of construction type bids, the second-best price would be second lowest. The benchmarking model could make it difficult for colluding firms to determine the price that would win the tender, thus negating the effects of a cover pricing scheme or complementary bids, and this is currently being considered by SANRAL and National Treasury.

- Transparent tender evaluation and adjudication processes. It is important to have a good tender document to avoid scope for bidders to manipulate the process. It should be a standard requirement that the supply chain management framework is structured such that there are separate committees managing the development of specifications, evaluation of bids and the award of tenders. And that the decision for the tender award, and reasons thereof, should be communicated to all firms that bid.

- Improved project management capacity in the public sector to ensure that projects are completed within the specified cost, quality and time. This has to be complemented by a clear governance framework with strict monitoring and evaluation of projects.

\subsection{Firm level}

For there to be a culture of competition in the construction sector, firms have a pivotal role to play. Competition, in essence, should take place between firms rather than the culture of cooperation through collusion and bid rigging. The cause of bid rigging, as most stakeholders noted, has been the entrenched culture of collusion that had for many years infiltrated the top tier of South African construction firms. The top-tier construction firms thus engaged in bid rigging to the detriment not only of clients but also the participation of emerging firms. As noted by Munshi (2013), "[e]merging contractors believe collusion robbed them of the opportunities to grow, for which they are entitled to restitution." In the absence of bid rigging, which occurred 
at least from 1999/2000 among the top-tier construction firms, it is conceivable that new firms could have emerged.

For instance, there are contracts that involved the construction of residential properties, roads and convention centres that would have provided the needed experience and exposure to the emerging firms in order achieve higher CDIB grading. In the case of the Netherlands, for example, firms involved in bid rigging engaged in predatory bidding to exclude emerging firms. Perhaps if some of the cases in South Africa are prosecuted, there could be better insights on the modus operandi of the bid rigging scheme. There is a need for a shift in the manner firms compete for projects, such that the culture of collusion and bid rigging is eradicated.

The firms involved in bid rigging on large infrastructure projects were, in the main, Group Five, Murray \& Roberts, Aveng, Stefanutti, Basil Read and Raubex. These are, historically, the established construction firms in South Africa. Most emerging contractors are not implicated in the bid rigging, as they are mainly roped into projects for limited subcontracting work. The toptier firms, having the wherewithal to undertake large infrastructure projects, opted to collude rather than compete, as the stakes were deemed high given the magnitude of the projects.

Despite the enactment of the CIDB Act in 2000 with the view to promote participation in the construction sector, construction firms that can grow to compete at the level of the top-tier firms have not emerged, which points to the challenges for emerging firms. Although there are over $50 \mathrm{CIDB}$ grade 9 construction firms, this has not translated into an increased level of competition in the space for large infrastructure projects. Some stakeholders ascribe this to the lack of an entrepreneurial culture among emerging construction firms, which tend to focus less on growing and building their businesses, and more on short-term financial gains. Others point to the lack of transformation of large construction firms, skills transfer and empowerment of the emerging construction firms (Munshi, 2013). The solution for meaningful participation by emerging firms in the construction sector can be found both in contractor development, as advocated by the CIDB, and in inculcating an entrepreneurial culture both for emerging and established firms.

Measures can be introduced to promote competition and participation in the construction sector such that the level of competition improves, including:

- Procurement integrity management system to improve transparency. In addition to the Certificate of Independent Bid Determination for public sector tenders, firms should be required to declare that there has been no instance of corruption in the bidding process such as kick-backs to clients, payments to other firms in relation to the bid, bribes etc.

- Adherence to the CIDB code of conduct for all parties involved in construction procurement.

- Promotion of emerging construction firms through skills transfer and empowerment by the large construction firms.

- Promoting competition by involving foreign construction firms in large infrastructure projects.

According to Dorée (2004), there is a risk that construction firms, in the case of the Netherlands, will revert to collusive practices if appropriate structural and behavioural remedies are not adopted. However, firms ought to be aware that there are potential costs of engaging in collusion, with far-reaching consequences. There are costs for firms that engage in bid rigging, as this takes management time to productively work on the business to increase productivity, 
innovate and grow the business. Firms have to do more than comply with regulations: they need to change their behaviour in order to eradicate the culture of collusion in their businesses.

\section{CONCLUSION}

Efficient procurement of construction services in large infrastructure projects hinges on the competitiveness of the construction sector as well as procurement practices. Bid rigging in construction has been uncovered in many countries, which points to the need for robust regulation to ensure firms are incentivised to compete and that conditions are favourable for emerging firms to compete. The challenge of bid rigging is also more pronounced in large infrastructure projects, where there are generally few firms with the capacity to compete for such projects.

The CIDB can play a more active role in limiting construction sector cartels in large infrastructure projects, particularly if it is granted sufficient powers to sanction firms that may be involved in collusive practices and also promote the participation of emerging firms to challenge the stranglehold of the top-tier construction firms. The sanctions should be complementary, rather than supplant the mandate of the CCSA.

This article proposed interventions that could be necessary at the regulatory, procurement and firm level to ensure that the construction sector charts a new sustainable competitive path. The interventions could ensure that a sound regulatory framework is designed for firms to compete fairly and that infrastructure projects clients get value for money.

With the mix of the proposed interventions at the regulatory, procurement and firm level, the South African construction industry could be less susceptible to collusive practices and, to a large extent, any other procurement irregularities.

\section{Acknowledgement}

This article draws on research undertaken as part of the Regulatory Entities Capacity Building Project, with funding from the South African government's Economic Development Department.

\section{LIST OF REFERENCES}

Competition Commission of South Africa (CCSA). (2013). Media Release: Construction firms settle collusive tendering cases with Rl.5 billion in penalties'. Competition Commission of South Africa. 24 June 2013.

CIDB Act. 2000. 'Construction Industry Development Board Act no. 38 of 2000'. Republic of South Africa

Cloete, N. (2013). Views on the role of CIDB in limiting construction sector collusion. [Interview]. G. Liviero Civils. 5 November 2013.

Competition Tribunal. (2013). Consent Order: In the matter between Competition Commission and Aveng (Africa) Ltd. Competition Tribunal of South Africa. 
Competition Tribunal. (2013a). Transcripts: Consent Order: in the matter between Competition Commission and various construction companies'. Competition Tribunal of South Africa.

Competition Tribunal. (2010). Competition Commission v Southern Pipelines Contractors/Conrite Walls, Case number: 23/CR/Feb09. Competition Tribunal of South Africa.

Dorée, A.G. (2004). Collusion in the Dutch construction industry: An industrial organization perspective. Building and Research Information,32(2), pp. 146-156.

Goeree, J.K. \& Offerman, T. (2004). 'The Amsterdam Auction'. Econometrica, 72(1), pp. 281-294.

Gupta, S. (2001). The Effect of Bid Rigging on Prices: A Study of the Highway Construction Industry. Review of Industrial Organization, 19(4), pp. 453-467.

Haberbush, K.L. (2000). Limiting the Government's Exposure to Bid Rigging Schemes: A Critical look at the Sealed Bid Rigging Regime. Public Contract Law Journal, 30 (1), pp. 97-122.

Jardine, R. (2013). Rejecting collusion and corruption: where to for the government and the private sector. Public lecture delivered at the Wits Business School on 8 October 2013. politicsweb. 9 0ctober. [Online] Available:

http://politicsweb.co.za/politicsweb/view/politicsweb/en/page71619? oid=415980\&sn=Detail\&pid=7 1616. (Accessed 13 December 2013)

Khumalo, J., Mashiane, J. \& Roberts, S. (2014). Harm and overcharge in the South African precast concrete products cartel. Journal of Competition Law and Economics, 10(3), pp. 621-646.

Klemperer, P. (2004). Auctions: Theory and Practise. Princeton University Press.

Lee, K.I. \& Hahn, K. (2002). 'Bid Rigging in Auctions for Korean Public-Works Contracts and Potential Damage'. Review of Industrial Organization, 21(1), pp. 73-88.

Marsden, M. (2013). City of Cape Town. Views on the role of CIDB in limiting construction sector collusion. [Interview]. 4 November 2013.

Mofokeng, G. (2013). Views on the role of CIDB in limiting construction sector collusion. [Interview]. Fikile Construction. 7 November 2013.

Munshi, R. (2013). Construction: New structure wanted, Financial Mail. 6-11 December. 34.

Ntiisa, K. and George, B. (2013). Views on the role of CIDB in limiting construction sector collusion. [Interview]. CIDB. 4 November 2013.

0ECD. (2012). Recommendation of the Council on Fighting Bid Rigging in Public Procurement. Organisation for Economic Cooperation and Development, Belgium.

0ECD. (2009). Guidelines for Fighting Bid Rigging in Public Procurement: Helping Governments to obtain Best Value for Money. Organisation for Economic Cooperation and Development, Belgium.

OFT. (2010). Evaluation of the impact of the OFT's investigation into bid rigging in the construction industry. A report prepared for the erstwhile Office of Fair Trading by Europe Economics. Office of Fair Trading, United Kingdom.

Porter, R.H. \& Zona, J.D. (1993). Detection of Bid Rigging in Procurement Auctions. Journal of Political Economy, 101(3), pp. 518-538.

Riley, J.G. \& Samuelson, W.F. (1981). Optimal Auctions. The American Economic Review, 71 (3), pp. 381-392. 


\section{Ratshisusu}

Smit, K. \& Van der Walt, C. (2013). Views on the role of CIDB in limiting construction sector collusion. [Interview]. SANRAL. 19 November 2013.

Sohail, M. \& Cavill, S. (2008). Accountability to Prevent Corruption in Construction Projects. Journal of Construction Engineering and Management, 134(9), pp. 729-738. 